\title{
The predictive value of magnetic resonance imaging in evaluating intracranial arteriovenous malformation obliteration after stereotactic radiosurgery
}

\author{
Cheng-Chia Lee, MD, ${ }^{1,4,5}$ Michael A. Reardon, MD, ${ }^{3}$ Benjamin Z. Ball, BS, ${ }^{1}$ Ching-Jen Chen, MD, ${ }^{1}$ \\ Chun-Po Yen, MD, ${ }^{1}$ Zhiyuan Xu, MD, ${ }^{1}$ Max Wintermark, MD, ${ }^{6}$ and Jason Sheehan, MD, PhD ${ }^{1,2}$ \\ Departments of ${ }^{1}$ Neurological Surgery, ${ }^{2}$ Radiation Oncology, and ${ }^{3}$ Radiology \& Medical Imaging, Neuroradiology Division, \\ University of Virginia Health System, Charlottesville, Virginia; ${ }^{4}$ Department of Neurosurgery, Neurological Institute, Taipei \\ Veterans General Hospital; ${ }^{5}$ School of Medicine, National Yang-Ming University, Taipei, Taiwan, Republic of China; and \\ ${ }^{6}$ Department of Radiology, Stanford University, Palo Alto, California
}

\begin{abstract}
OBJECT The current gold standard for diagnosing arteriovenous malformation (AVM) and assessing its obliteration after stereotactic radiosurgery (SRS) is digital subtraction angiography (DSA). Recently, MRI and MR angiography (MRA) have become increasingly popular imaging modalities for the follow-up of patients with an AVM because of their convenient setup and noninvasiveness. In this study, the authors assessed the sensitivity and specificity of MRI/MRA in evaluating AVM nidus obliteration as assessed by DSA.

METHODS The authors study a consecutive series of 136 patients who underwent SRS between January 2000 and December 2012 and who underwent regular clinical examinations, several MRI studies, and at least 1 post-SRS DSA follow-up evaluation at the University of Virginia. The average follow-up time was 47.3 months (range 10.1-165.2 months). Two blinded observers were enrolled to interpret the results of MRI/MRA compared with those of DSA. The sensitivity, specificity, positive predictive value, and negative predictive value for the obliteration of AVM were reported.
\end{abstract}

RESULTS On the basis of DSA, 73 patients (53.7\%) achieved final angiographic obliteration in a median of 28.8 months. The sensitivity (the probability of finding obliteration on MRI/MRA among those for whom complete obliteration was shown on DSA) was $84.9 \%$ for one observer (Observer 1) and $76.7 \%$ for the other (Observer 2). The specificity was $88.9 \%$ and $95.2 \%$, respectively. The false-negative interpretations were significantly related to the presence of draining veins, perinidal edema on T2-weighted images, and the interval between the MRI/MRA and DSA studies.

CONCLUSIONS MRI/MRA predicted AVM obliteration after SRS in most patients and can be used in their follow-up. However, because the specificity of MRI/MRA is not perfect, DSA should still be performed to confirm AVM nidus obliteration after SRS.

http://thejns.org/doi/abs/10.3171/2014.10.JNS141565

KEY WORDS obliteration; Gamma Knife; stereotactic radiosurgery; arteriovenous malformation; MRI; digital subtraction angiography; vascular disorders

$\mathrm{T}$ HE gold standard for diagnosing an arteriovenous malformation (AVM) nidus and evaluating the post-stereotactic radiosurgery (SRS) obliteration is cerebral angiography, which in current radiological terminology is called digital subtraction angiography (DSA). Over the past 3 decades, confirmation of AVM obliteration after SRS has been obtained by using DSA. However, patients often opt not to undergo angiography, especially when they experience no AVM-related symptoms. In ad- dition to procedural complications, $3,7,8,12,13$ patients usually experience some unpleasant sensations during angiography, including pain, heat, invasiveness, and radiation exposure, and prolonged bed rest after the procedure. The cost associated with DSA examinations can also be significant. With MRI/MR angiography (MRA), the convenience and noninvasiveness of the studies appeal to physicians and patients.

At the University of Virginia, MRI in conjunction with

ABBREVIATIONS AVM = arteriovenous malformation; DSA = digital subtraction angiography; FSE = fast spin echo; GKS = Gamma Knife surgery; MRA = MR angiography; ROC = receiver operating characteristic; SRS = stereotactic radiosurgery; $\mathrm{T} 1 \mathrm{WI}=\mathrm{T} 1$-weighted imaging; $\mathrm{T} 2 \mathrm{WI}=\mathrm{T}$-weighted imaging; $\mathrm{TOF}=$ time of flight. SUBMITTED July 8, 2014. ACCEPTED October 8, 2014.

INCLUDE WHEN CITING Published online April 3, 2015; DOI: 10.3171/2014.10.JNS141565.

DISCLOSURE The authors report no conflict of interest concerning the materials or methods used in this study or the findings specified in this paper. 
MRA has been used with minimal adverse effects in the routine radiological follow-up of patients with an AVM. Once the nidus has been shown on MRA images to be obliterated or the nidus has been persistently patent for the maximal follow-up time, patients are recommended to undergo DSA examination. In the current study, we retrospectively assessed the sensitivity and specificity of MRI/ MRA in evaluating nidus obliteration and compared its efficacy to that of the gold standard, DSA. Factors associated with false-positive or -negative obliterations using MRI/MRA were also analyzed.

\section{Methods \\ Patients}

A consecutive series of 483 patients with an AVM underwent Gamma Knife surgery (GKS) between January 2000 and December 2012. Of these patients, 136 (28\%) with regular clinical examinations, several MRI studies, and at least 1 post-GKS DSA follow-up at the University of Virginia were included in this study. Clinical data, including patient demographics, imaging results, and radiosurgical parameters, were reviewed retrospectively from a database prospectively approved by the University of Virginia institutional review board.

Each patient underwent a comprehensive neurological examination and a cerebral imaging evaluation before radiosurgery. Bleeding history, age of the patient, existing comorbidities, location of the nidus, Spetzler-Martin grade of the AVM, previous treatment history, and clinical symptomatology were reviewed. Neurodiagnostic imaging included both an intravenous paramagnetic contrastenhanced 3D volumetric MRI scan and a whole-head T2-weighted fast spin-echo (FSE) imaging sequence. Subsequently, each patient underwent biplanar DSA. MRI scans with DSA images are more helpful in developing 3D conformal plans than using 2D angiography only.

\section{Stereotactic Radiosurgery}

Our SRS technique was described previously. ${ }^{15,16,31,32}$ Radiosurgery was performed by using a Leksell gamma unit model 4C between 2000 and 2007 and the Perfexion model (Elekta) thereafter. Because precise localization of portions of the nidus was not achieved by using DSA in the anterior-posterior plane, 3D imaging via MRI was necessary to establish better localization. Radiosurgical parameters and dose plans were formulated by the treating neurosurgeon in consultation with a medical physicist and a radiation oncologist. The dose to the surrounding brain is a critical predictor of adverse radiation effects; therefore, one should carefully consider maximizing conformality and avoiding any identifiable portion of eloquent brain parenchyma.

\section{Imaging Evaluations}

After SRS treatment, each patient underwent clinical evaluation and MRI/MRA studies at 6-month intervals. To minimize the MRI sequencing difference from other institutions, we included only the patients who underwent a series of neuroimaging studies at the University of Virginia. At the University of Virginia during the study period, the MRI/MRA protocol was fairly consistent, with minor variations resulting from improvements in MRI technology. The protocol for MRI/MRA follow-up in patients after GKS for an AVM is distinct from that in patients after GKS for other conditions; this follow-up includes evaluation for the presence of not only abnormal vasculature but also perinidal parenchymal edema. The flow of the abnormal vessels and the content of draining veins were also important. Therefore, the MRI/MRA protocol routine included thin-sliced T1-weighted imaging (T1WI) with and without contrast, FSE T2-weighted imaging (T2WI), and 3D time-of-flight (TOF) MRA source images. T1WI helps to interpret the possibility of the presence of subacute hematoma/thrombus and hemosiderinladen gliotic brain tissue. T2WI helps clinicians to evaluate the severity of perinidal brain edema. 3D-TOF MRA displays the flow and existence of the nidus.

Total obliteration of the AVM after radiosurgery was defined as the complete absence of the former nidus, normalization of afferent and efferent vessels, and normal circulation time as determined with high-quality rapid serial DSA. Any remaining nidus, regardless of its size, was considered "patent" in this study, including the existence of early-filling draining veins. Although it may be difficult to determine the existence of early-filling draining veins with MRI/MRA, we shared the same rationale when we interpreted obliteration of an AVM on a MRI/MRA study; any residual nidus was considered patent in this study. Original interpretation of the angiograms to determine patency or obliteration of the nidus was performed by a senior neurologist (M.W.) and a senior neurosurgeon (J.S.).

For the sake of assessing the predictive value of MRI/ MRA, 2 observers were enrolled in the study: an experienced neurosurgeon (C.C.L.) and an experienced neuroradiologist (M.A.R). These observers were blinded to patient name, clinical conditions, and image reports. For the assessments for obliteration, the observers were also blinded to the DSA results previously interpreted by the senior neuroradiologist and the senior neurosurgeon. The results were analyzed by the other coauthors.

To analyze the potential factors that cause false-positive and -negative determinations of obliteration in MRI/ MRA studies, radiological features in these studies that can affect imaging interpretation were collected. These features include the presence and numbers of draining veins, the presence of brain edema as determined by T2WI, and the presence of contrast enhancement within the nidus. The interval between the MRI/MRA and DSA studies was also analyzed.

\section{Statistical Analysis}

Descriptive statistics for all data are presented as medians and ranges for continuous variables and as numbers and percentages for categorical variables. Potential prognostic variables associated with false-positive and -negative results, including the nidus volume, AVM grade, previous hemorrhage, previous resection, previous embolization, presence of a draining vein, presence of T2 signal changes, presence of contrast enhancement, and interval between the MRI and DSA studies, were evaluated using logistic univariate and multivariate analyses. Statistical 
significance was defined as a $p$ value of $<0.05$. All analyses were completed by using commercial statistical software (IBM SPSS version 20.0).

In this study, the sensitivity, specificity, positive predictive value, and negative predictive value for an AVM obliteration were reported. Sensitivity was defined as the probability of finding obliteration on MRI/MRA among those for whom complete obliteration was shown on DSA. Specificity was defined as the probability of finding a patent nidus among those for whom a patent nidus was shown on DSA. Positive predictive value was defined as the probability of finding a case in which the nidus was diagnosed as obliterated on MRI/MRA and in which it was confirmed on DSA. Negative predictive value was defined as the percentage of cases in which the nidus was diagnosed as patent on MRI/MRA and in which it was confirmed on DSA. For differentiating a patent from an obliterated AVM on MRI/MRA compared with those determined on DSA, each observer also performed receiver operating characteristic (ROC) analysis.

\section{Results}

\section{Patient Demographics and AVM Characteristics}

The median age of the patients was 36 years (range 4-73 years), and the female/male sex distribution was 73:63. The median nidus volume, based on volumetric calculations from MR images, was $2.1 \mathrm{~cm}^{3}$ (range 0.1-21.0 $\left.\mathrm{cm}^{3}\right)$. Most patients $(\mathrm{n}=106,77.9 \%)$ had an AVM nidus located in a hemispheric lobe. Spetzler-Martin grades were used to classify the AVMs of these patients: 115 nidi $(84.6 \%)$ were $<3 \mathrm{~cm}, 20$ nidi $(14.7 \%)$ were between 3 and $6 \mathrm{~cm}$, and 1 nidus $(0.7 \%)$ was $>6 \mathrm{~cm} ; 70$ nidi $(51.5 \%)$ were located in a noneloquent area, and 66 nidi $(48.5 \%)$ were located in an eloquent area; and 77 nidi (56.6\%) had superficial venous drainage only, and the other 59 nidi (43.4\%) had $\geq 1$ deep draining veins.

Fifty-eight patients $(42.6 \%)$ had hemorrhage episodes before SRS, and 30 patients (22.1\%) had seizure episodes; other symptoms included headache in 30 (22.1\%), cranial nerve palsy in $10(7.4 \%)$, visual field deficits in $8(5.9 \%)$, dysphasia in $6(4.4 \%)$, cerebellar sign in $5(3.7 \%)$, and long tract sign in 5 (3.7\%), among others. Fourteen patients $(10.3 \%)$ had received microsurgical AVM nidus resection with residue, whereas $31(22.8 \%)$ had $\geq 1$ previous embolization intervention. Fifteen patients (11.0\%) had previous fractionated radiation therapy. The median clinical followup time was 47.3 months (range 10.1-165.2 months), the median MRI follow-up duration was 42.6 months (range 8.6-147.3 months), and the median DSA follow-up time was 31.7 months (range 8.6-105.6 months) (Table 1). To validate the predictability of MRI/MRA in determining the obliteration of intracranial AVMs, we reviewed the pre-DSA MRI images, and the median pre-DSA MRI was performed 27.6 months (range 5.8-115.0 months) after SRS. The interval between the immediate previous MRI/ MRA and the subsequent DSA was 2.1 months (range 0-24.4 months).

\section{Imaging Outcome}

Table 2 shows the interpretations of the MRI/MRA
TABLE 1. Characteristics in 136 patients with an AVM treated with SRS

\begin{tabular}{|c|c|c|}
\hline Characteristic & Value (Range) & $\%$ \\
\hline Median age (yrs) & $36(4-73)$ & \\
\hline $\operatorname{Sex}(F / M)$ & $73: 63$ & \\
\hline Median nidus vol $\left(\mathrm{cm}^{3}\right)$ & $2.1(0.1-21.0)$ & \\
\hline \multicolumn{3}{|l|}{ AVM location (no.) } \\
\hline Lobar & 106 & 77.9 \\
\hline Basal ganglia and thalamic & 18 & 13.2 \\
\hline Cerebellum & 7 & 5.1 \\
\hline Brainstem & 5 & 3.7 \\
\hline \multicolumn{3}{|l|}{ AVM grading (S-M grade) } \\
\hline \multicolumn{3}{|l|}{ Size (no.) } \\
\hline Small $(<3 \mathrm{~cm})$ & 115 & 84.6 \\
\hline Medium $(3-6 \mathrm{~cm})$ & 20 & 14.7 \\
\hline Large (>6 cm) & 1 & 0.7 \\
\hline \multicolumn{3}{|l|}{ Eloquence of adjacent brain (no.) } \\
\hline Noneloquent & 70 & 51.5 \\
\hline Eloquent & 66 & 48.5 \\
\hline \multicolumn{3}{|l|}{ Pattern of venous drainage (no.) } \\
\hline Superficial only & 77 & 56.6 \\
\hline Deep & 59 & 43.4 \\
\hline No. w/ previous intracranial hemorrhage & 58 & 42.6 \\
\hline No. w/ previous seizures & 30 & 22.1 \\
\hline No. w/ previous resection of nidus & 14 & 10.3 \\
\hline No. w/ previous embolization & 31 & 22.8 \\
\hline No. w/ previous radiation therapy & 15 & 11.0 \\
\hline No. w/ upfront SRS & 86 & 63.2 \\
\hline Median clinical FU time (mos) & $47.3(10.1-165.2)$ & \\
\hline Median MRI FU time (mos) & $42.6(8.6-147.3)$ & \\
\hline Median pre-DSA MRI FU time (mos) & $27.6(5.8-115.0)$ & \\
\hline Median DSA FU time (mos) & $31.8(8.6-123.2)$ & \\
\hline \multicolumn{3}{|l|}{ SRS treatment parameters (median) } \\
\hline Margin radiation dose (Gy) & $23(13-25)$ & \\
\hline Maximal radiation dose (Gy) & $46(26-50)$ & \\
\hline Isodose level (\%) & $50(50-76)$ & \\
\hline
\end{tabular}

FU = follow-up; S-M = Spetzler-Martin.

and DSA images according to the 2 observers. In the current series, final angiographically determined obliteration was achieved in 73 patients $(53.7 \%$ ) in a median of 28.8 months. In the other 63 patients a patent nidus was diagnosed. Although they were blinded to each other's imaging interpretations, both observers (the neurosurgeon and the neuroradiologist) reached a consensus for these 73 patients with an obliterated AVM as confirmed by DSA.

However, discrepancies between the 2 observers occurred when they used MRI/MRA to determine the obliteration of a post-GKS nidus. For Observer 1, 7 cases were false positive when interpreted using MRI/MRA and 11 cases were false negative when interpreted using MRI/ MRA. For Observer 2, 3 cases were false positive when interpreted using MRI/MRA and 17 cases were false neg- 
TABLE 2. Determination of nidus on MRI/MRA and DSA and predictive value of MRI/MRA for definitive obliteration in comparison with DSA

\begin{tabular}{|c|c|c|c|c|}
\hline \multirow[b]{2}{*}{ DSA } & \multicolumn{2}{|c|}{$\begin{array}{l}\text { MRI/MRA } \\
\text { Observer } 1\end{array}$} & \multicolumn{2}{|c|}{$\begin{array}{l}\text { MRI/MRA } \\
\text { Observer } 2\end{array}$} \\
\hline & Patent & Obliterated & Patent & Obliterated \\
\hline Patent (no.) & 56 & 7 & 60 & 3 \\
\hline Obliterated (no.) & 11 & 62 & 17 & 56 \\
\hline Prevalence $(\%)^{*}$ & \multicolumn{2}{|r|}{53.7} & \multicolumn{2}{|r|}{53.7} \\
\hline Sensitivity (\%) & \multicolumn{2}{|r|}{84.9} & \multicolumn{2}{|r|}{76.7} \\
\hline Specificity (\%) & \multicolumn{2}{|r|}{88.9} & \multicolumn{2}{|r|}{95.2} \\
\hline $\begin{array}{l}\text { Positive predictive } \\
\text { rate }(\%)\end{array}$ & \multicolumn{2}{|r|}{89.9} & \multicolumn{2}{|r|}{94.9} \\
\hline $\begin{array}{l}\text { Negative predictive } \\
\text { rate }(\%)\end{array}$ & \multicolumn{2}{|r|}{83.6} & \multicolumn{2}{|r|}{77.9} \\
\hline False-positive rate (\%) & \multicolumn{2}{|r|}{10.1} & \multicolumn{2}{|r|}{5.1} \\
\hline $\begin{array}{l}\text { False-negative rate } \\
\qquad(\%)\end{array}$ & \multicolumn{2}{|r|}{16.4} & \multicolumn{2}{|r|}{22.1} \\
\hline
\end{tabular}

* Prevalence of obliteration after SRS for an intracranial AVM.

ative when interpreted using MRI/MRA (Table 2). The sensitivity (i.e., the probability of finding obliteration on MRI/MRA among those for whom complete obliteration was shown on DSA) was $84.9 \%$ for Observer 1 and $76.7 \%$ for Observer 2. The specificity for Observer 1 was $88.9 \%$ and that for Observer 2 was 95.2\%. The positive predictive rates for the 2 observers were $89.9 \%$ and $94.9 \%$ and the negative predictive rates were $83.6 \%$ and $77.9 \%$, respectively (Table 2).

Combining the interpretations from both observers, 9 cases with 10 observations were interpreted as false positives and 19 cases with 28 observations were interpreted as false negatives. The false-positive and false-negative rates varied: $10.1 \%$ and $16.4 \%$ for Observer 1 and $5.1 \%$ and $22.1 \%$ for Observer 2 , respectively. The frequency of false-positive interpretations of AVM obliterations on MRI/MRA was less than that of false-negative interpretations (10 vs 28 observations, respectively). Figures 1 and 2 illustrate cases for which there was a false-positive and a false-negative interpretation, respectively.

To analyze what caused false interpretations, several factors were included in a logistic regression model. Table 3 shows that the false-positive interpretations were not related to AVM volume, Spetzler-Martin grade, previous hemorrhage, previous resection, previous embolization, previous radiotherapy, AVM location, presence of draining veins, presence of brain edema with T2 signal changes, presence of contrast enhancement within the nidus, or time interval between MRI/MRA and DSA. In contrast, the presence of draining veins, perinidal edema on T2WI, and time interval between MRI/MRA and DSA were significantly associated with false-negative interpretations. The other factors we evaluated were not significantly associated with false-negative interpretations.

For differentiating a patent nidus from an obliterated nidus on MRI/MRA in comparison with DSA, ROC analysis resulted in areas under the ROC curve for predicting obliteration of 0.861 for Observer 1 and 0.844 for Observer 2 (Fig. 3).

\section{Discussion}

Complete AVM obliteration after SRS is critical for reducing the risk of hemorrhage from the nidus. ${ }^{20}$ Thus, the primary end point in AVM radiosurgery is usually complete obliteration. Because of its high spatial and temporal resolution, DSA is the gold standard diagnostic modality for determining nidus obliteration. ${ }^{25,33}$ Previous studies have recommended that clinicians acquire follow-up DSA images for AVM patients for 2 to 4 years after SRS to determine the appropriate management strategies, such as observation, repeat SRS, embolization, and resection. ${ }^{40,41}$ Although the morbidity and mortality rates associated with DSA are low, several studies involving DSA have found significant complication rates and decreased compliance of patients in continuing with the recommended treatment. . $7,8,12,13,18,21$ In contrast, the complication rate for MRI is lower than that for DSA. ${ }^{39}$ In several small reports, MRA-based images might be used as the sole follow-up imaging modality for radiosurgery of AVMs that are less than $3 \mathrm{~cm}^{3}$ when they are in a noneloquent location. ${ }^{5}$

In this study, we evaluated whether MRI/MRA can replace DSA for determining AVM obliteration after SRS. For patients who were believed to have nidus obliteration shown on MRI/MRA, high positive predicative values of $89.9 \%$ and $94.9 \%$ were observed between the 2 observers in this study. MRI/MRA seems to be a reasonable but imperfect modality for determining nidus obliteration in patients with an AVM treated by SRS. Although we did not specifically address the value of DSA targeting at the time of SRS, the value of DSA for confirming obliteration intuitively seems to convey an importance for DSA targeting along with routine stereotactic MRI at the time of SRS.

However, false-positive and -negative interpretations of MRI/MRA were still evident, which may carry important implications. Partial obliteration of an intracranial AVM may be detrimental to the patient,${ }^{39}$ because false-positive obliteration according to MRI/MRA can result in suboptimal salvage therapy. Several authors have suggested that after SRS, progressive narrowing of the vessel caliber is attributed to the proliferation of the endothelial layer of these vessels. ${ }^{6,17,19,29,30}$ Concurrently, the blood flow velocity through the vessel increases initially before decreasing and ultimately coming to a halt with the development of an intraluminal thrombus. Because the visibility of vessels in MRA depends on blood flow, false-positive interpretation via this modality can be expected when the blood flow velocity is slow enough. Although there is no strong evidence to support the idea that there is a definitive low limit of blood flow that can be seen in MRA, a limitation exists in the smaller, slow-flow, and residual vessels. Mukherji et al. ${ }^{22}$ found that a nidus of $<10 \mathrm{~mm}$ is a key factor for false interpretation of nidus obliteration via MRI/MRA. MRI/MRA offered $95 \%$ sensitivity and $100 \%$ specificity for depicting a residual nidus, provided that an arteriovenous shunt and a residual nidus of $1 \mathrm{~cm}$ remained. With gradient-echo imaging, the sensitivity did 

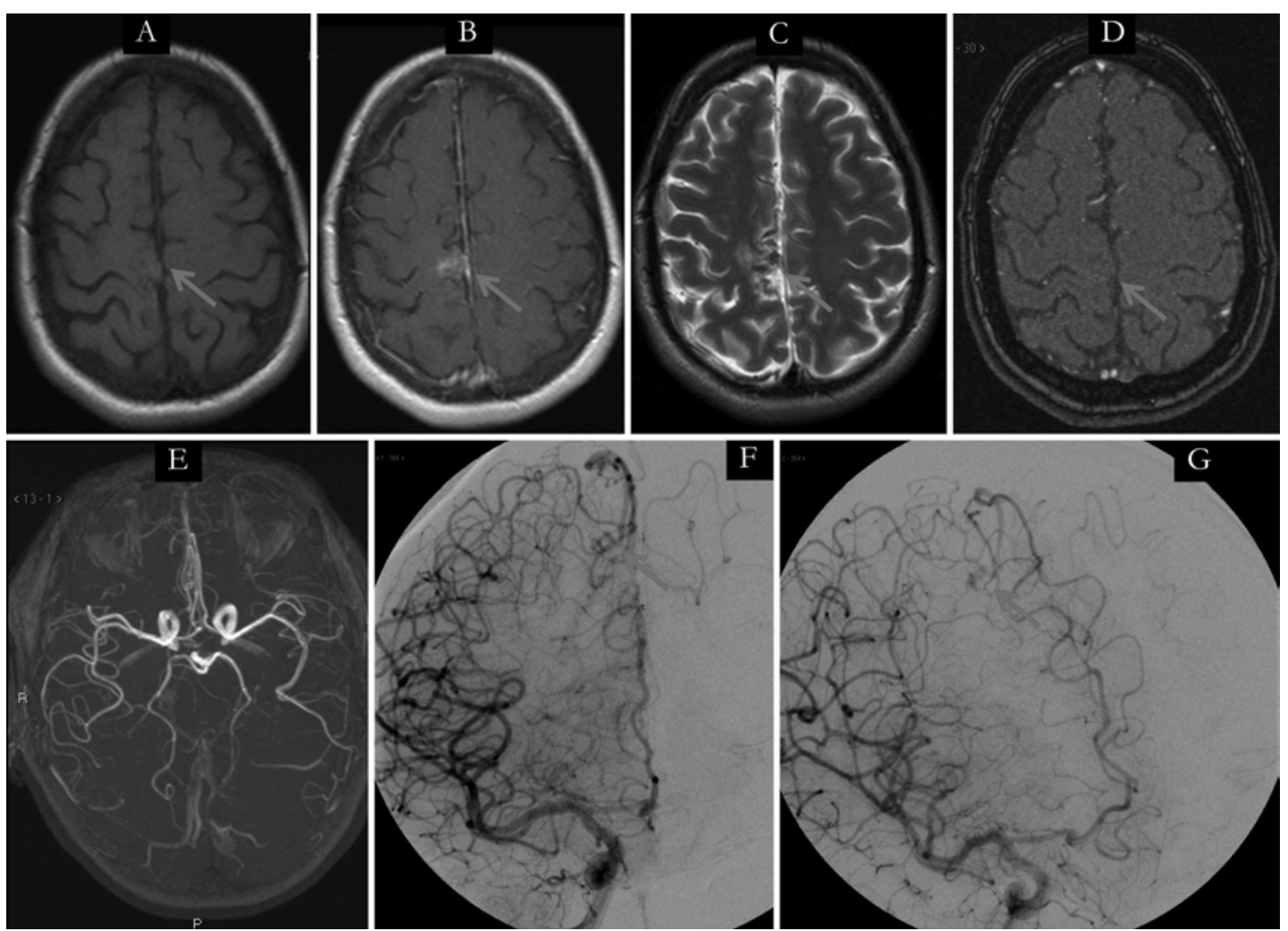

FIG. 1. Illustration of a case with false-positive interpretation of AVM nidus obliteration in a 36-year-old woman with a 5-cm ${ }^{3}$ right paracentral AVM after embolization. Both blinded observers determined this AVM to be obliterated according to an MRI study 44 months after SRS. There is no subacute hematoma shown in T1WI (A), a possible thrombus formation shown in T2WI (C), and no significant flow shown in MRA ( $D$ and $E$ ). However, DSA ( $F$ and $\mathbf{G})$, performed 6 weeks after MRI, shows a small nidus with early venous drainage near the sagittal sinus. Postcontrast enhancement can be seen in T1WI (B). There was no draining vein seen in postcontrast imaging. Arrows in A-D, F, and $\mathrm{G}$ point to the location of the nidus.

not become $100 \%$ until the nidus diameter was $0.36 \mathrm{~cm}$, whereas compared with DSA results, 1.5-T MRA without contrast detected $81 \%-99 \%$ of intracranial vessels with a diameter of $\leq 1 \mathrm{~mm} \cdot{ }^{34}$

In addition to vessel diameters and blood flow velocity, there are multiple factors that may influence the visibility of vessels in MRI/MRA, including the intensity of the magnetic field, parameters of echo time, repetition time, and flip angle, the use of saturation band, the thickness of every slice, the direction of blood flow, and the image angle of the blood flow. ${ }^{26,36}$ Even the type of flow, such as turbulent flow, may decrease the signal intensity. ${ }^{37}$ Accompanying the dynamic changes of AVM after SRS, the signal intensity changes continuously, which makes the interpretation of MRA challenging. Finally, the AVM and normal brain may have common draining veins, which causes difficulties in interpreting obliteration of the nidus. In theory, these veins will never disappear completely. Nevertheless, from the factors analyzed in this study, the presence of a draining vein, perinidal edematous changes on T2WI, and contrast enhancement were not related to false-positive interpretations, which also reflects the meticulous interpretations of the neurosurgeons and neuroradiologists at our center.

In contrast to false-positive results, false-negative results are often overlooked in current and previous reports. ${ }^{4}$
The false-negative interpretation of obliteration on the basis of MRI/MRA may result in a patient receiving unnecessary interventions, leading to extraneous potential risks associated with these interventions. In earlier studies, the precontrast high-intensity signals and contrast enhancement within the nidus of AVMs caused by hematoma or thrombus formation interfered with the interpretation of AVM obliteration. ${ }^{38}$ In current clinical practice, we recommend reviewing the spin-echo T1WI, FSE T2WI sequences, and 3D-TOF MRA sequences simultaneously to better exclude the presence of a subacute hematoma/ thrombus and hemosiderin-laden gliotic brain tissue, which all have a high signal intensity in lesions in TOF MRA images. Because 3D-TOF MRA is also a T1-based technique, coagulated or slow-flowing blood might present as a hyperintense signal as well. The combination of T1WI and 3D-TOF MRA might overcome the misinterpretation of stagnant nidal blood flow as persistent flow. ${ }^{4}$ According to our analysis, the presence of a draining vein and interference of perinidal edema on T2WI were related to false-negative interpretations, which indicates that the presence of a drainage vein may occur when an intracranial AVM is obliterated, and the extent of perinidal edema may be independent of AVM obliteration. Another factor associated with false-negative interpretations is prolonged time intervals ( $>6$ months) between MRI and DSA. A lon- 

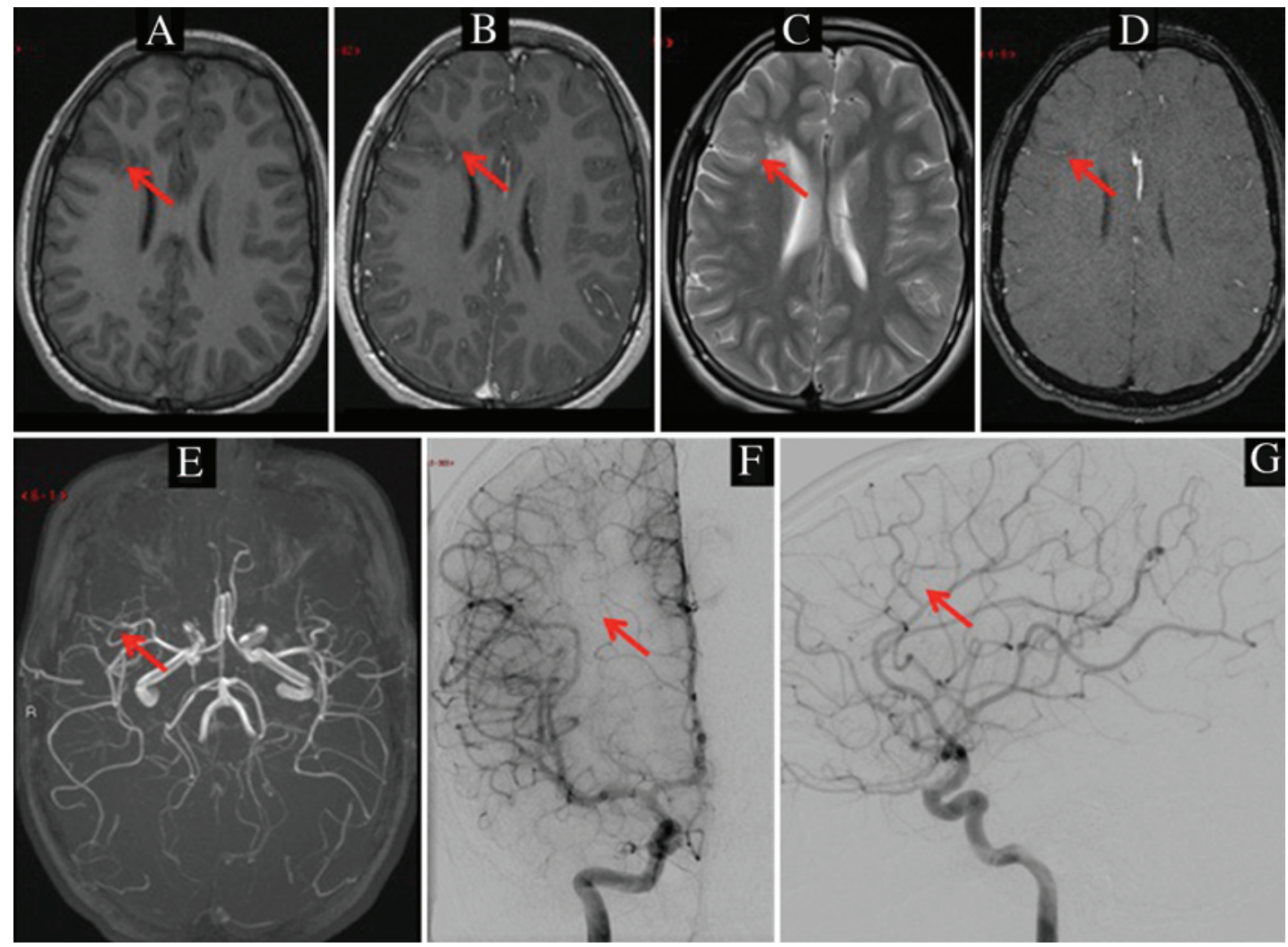

FIG. 2. Illustration of a case with false-negative interpretation of $A V M$ nidus obliteration in an 11-year-old boy with a $0.7-\mathrm{cm}^{3} \mathrm{AVM}$ nidus in the right frontal region. Because of a persistent fine, linear, branching contrast enhancement (probably vessels) that is not present on T1WI (A), T1WI with contrast (B), T2WI (C), or TOF MRA (D and E) and may be related to slow flow, both observers had difficulty judging whether this AVM was obliterated. In addition, an unchanged susceptibility artifact in this region was consistent with hemosiderin-laden gliotic brain tissue. The T2 signal hyperintensity surrounding the nidus also confounded the accurate interpretation. DSA performed 2 weeks after MRI (F and $\mathbf{G}$ ) shows no evidence of shunting or a nidus, thereby confirming AVM obliteration. Red arrows in A-G point to the location of the nidus. Figure is available in color online only.

ger interval usually results in false-negative interpretation via MRI/MRA. The changes in AVM angioarchitecture after SRS may be more rapid than previously believed. Therefore, we recommend that DSA be performed within 3 months of obliteration confirmation via MRI/MRA.

Although we did not exclude the AVMs with previous embolization, we initially expected the embolic agents to affect the interpretation of obliteration. However, previous embolization was not related to either false-positive or -negative interpretation according to logistic model analysis $(p=0.803$ and 0.300 , respectively). Although reports do not definitively show that embolic agents influence the interpretation of AVM obliteration, several studies demonstrated that embolic agents, including detachable microcoil, polyvinyl alcohol, $N$-butyl-2-cyanoacrylate, and isobutyl-2-cyanoacrylate, may interfere with SRS dose planning. ${ }^{9,11,27,28}$ For instance, embolization may obscure the margin of the nidus and thereby mislead to an optimal interpretation. ${ }^{27}$ Also, dose planning may be more difficult if the AVM nidus is segmented into discrete noncontiguous portions, and the nidus may be obscured on MRI and even biplanar angiography when microcoil or other embolic materials are used. Second, embolization may induce hypoxia, which makes the tissue less radiosensitive and increases the angiogenic activity of the AVM, ${ }^{2,35}$ rendering it a more active lesion. ${ }^{1,23}$ Therefore, these physical and biological effects should be considered carefully by the radiologist or neurosurgeon who reviews the postembolization AVMs.

The higher rate of false-negative than false-positive interpretations reflects the fact that our clinicians were looking carefully for radiological evidence of nidus obliteration and were likely biased to avoid false-negative interpretations before the patients underwent DSA. We tend to wait longer and collect more MRI evidence to prove that the SRS was successful before ordering DSA. In particular, MR sequences may prove helpful when clinicians face the dilemma of near-obliteration. For example, cine phasecontrast MRI may be an effective pulse sequence for helping us to investigate the hemodynamics of radiosurgical AVMs. ${ }^{14,24}$ Phase-contrast MRI offers co-registered morphological images and velocity data within a single acquisition. After acquiring and processing the data in morphological and phase-difference images, various visualization strategies enable qualitative analysis of hemodynamics. A number of quantitative parameters, such as pulse wave velocities and estimates of wall shear stress, which might serve as future biomarkers, can be extracted..$^{10}$ With cur- 
TABLE 3. Influential factors of false-positive and -negative interpretations of AVM obliteration on MRI/MRA (logistic regression model)

\begin{tabular}{|c|c|c|c|c|}
\hline \multirow[b]{3}{*}{ Factor } & \multicolumn{4}{|c|}{ p Value } \\
\hline & \multicolumn{2}{|c|}{ False-Positive Obliteration* } & \multicolumn{2}{|c|}{ False-Negative Obliteration† } \\
\hline & Univariate & Multivariate & Univariate & Multivariate \\
\hline AVM vol $\left(\mathrm{cm}^{3}\right)$ & 0.840 & - & 0.778 & - \\
\hline S-M grade & 0.347 & - & 0.404 & - \\
\hline Previous hemorrhage & 0.255 & - & 0.883 & - \\
\hline Previous resection & 0.845 & - & 0.423 & - \\
\hline Previous embolization & 0.803 & - & 0.300 & - \\
\hline Previous radiotherapy & 0.793 & - & 0.283 & - \\
\hline AVM location (lobar vs no lobar) & 0.276 & - & 0.125 & 0.218 \\
\hline Presence of draining vein & 0.637 & - & 0.057 & $0.048 \ddagger$ \\
\hline Presence of T2 changes & 0.051 & 0.057 & $0.018 \ddagger$ & $0.013 \ddagger$ \\
\hline Presence of enhancement & 0.712 & - & 0.583 & - \\
\hline MRI/MRA-to-DSA interval & 0.150 & 0.254 & $0.048 \ddagger$ & $0.046 \ddagger$ \\
\hline $\begin{array}{l}\text { = not applicable. } \\
\text { Nine cases and } 10 \text { observations. } \\
\text { Nineteen cases and } 28 \text { observations. } \\
\text { Boldface indicates statistical significanc }\end{array}$ & & & & \\
\hline
\end{tabular}

rent $2 \mathrm{D}$ sequences, the short scan time for a target vessel and the acquisition plane (should be vertical to the blood flow) limit the use of phase-contrast MRI. With the refinement of imaging techniques, future techniques in $3 \mathrm{D}$ or 4D phase-contrast flow studies may enable better assessment of AVM nidi after SRS.

\section{Study Limitations}

There were several limitations in this retrospective study, which involved a large number of patients treated at the University of Virginia, many of whom were from outside the United States or who traveled long distances for treatment. To avoid misinterpreting the MRI/MRA or

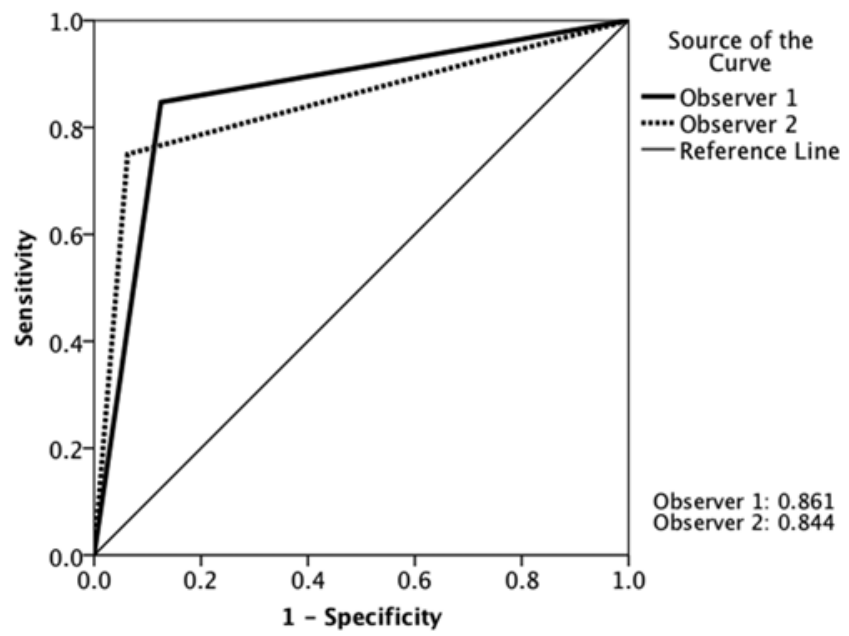

FIG. 3. ROC curves show good discriminating power, with areas under the curve of 0.861 (Observer 1) and 0.844 (Observer 2) for MRI/MRA differentiating obliteration of intracranial AVMs after SRS.
DSA images from variable sequences that were set by different hospitals, we included only the patients who were regularly followed up with neuroimaging studies at the University of Virginia (28\% of the total number of patients with an AVM during 2000-2012). These stringent criteria may have resulted in unintended selection bias. Although this was not a rigorously controlled study, the information provided remains precise and extensive for such a study design. In addition, over the time span of the study, more sophisticated MR sequences (e.g., cine phasecontrast studies) and higher-field-strength magnets (3-T vs 1.5-T MR machine) have improved the detection rate of small residual blood flow within nidi. Hence, image quality and nidus-obliteration detection may have varied slightly between earlier and more recently obtained MRI/ MRA studies.

\section{Conclusions}

MRI/MRA offers reasonable sensitivity and specificity for detecting nidus obliteration in patients with an AVM treated with SRS. The approximate sensitivity and specificity of MRI/MRA in this study were $80 \%$ and $90 \%$, respectively. The determination of obliteration by MRI/ MRA was limited by the presence of draining veins, T2 signal changes around the nidus, and prolonged time intervals between MRI/MRA and DSA acquisitions. Despite recent improvements in MRI techniques, DSA remains the definitive diagnostic modality for assessing complete AVM nidus obliteration after radiosurgery.

\section{References}

1. Achrol AS, Guzman R, Varga M, Adler JR, Steinberg GK, Chang SD: Pathogenesis and radiobiology of brain arteriovenous malformations: implications for risk stratification in 
natural history and posttreatment course. Neurosurg Focus 26(5):E9, 2009

2. Akakin A, Ozkan A, Akgun E, Koc DY, Konya D, Pamir MN, et al: Endovascular treatment increases but Gamma Knife radiosurgery decreases angiogenic activity of arteriovenous malformations: an in vivo experimental study using a rat cornea model. Neurosurgery 66:121-130, 2010

3. Bendszus M, Koltzenburg M, Burger R, Warmuth-Metz M, Hofmann E, Solymosi L: Silent embolism in diagnostic cerebral angiography and neurointerventional procedures: a prospective study. Lancet 354:1594-1597, 1999

4. Buis DR, Bot JC, Barkhof F, Knol DL, Lagerwaard FJ, Slotman BJ, et al: The predictive value of 3D time-of-flight MR angiography in assessment of brain arteriovenous malformation obliteration after radiosurgery. AJNR Am J Neuroradiol 33:232-238, 2012

5. Buis DR, Lagerwaard FJ, Dirven CM, Barkhof F, Knol DL, van den Berg R, et al: Delineation of brain AVMs on MRangiography for the purpose of stereotactic radiosurgery. Int J Radiat Oncol Biol Phys 67:308-316, 2007

6. Chang SD, Shuster DL, Steinberg GK, Levy RP, Frankel K: Stereotactic radiosurgery of arteriovenous malformations: pathologic changes in resected tissue. Clin Neuropathol 16:111-116, 1997

7. Dawkins AA, Evans AL, Wattam J, Romanowski CA, Connolly DJ, Hodgson TJ, et al: Complications of cerebral angiography: a prospective analysis of 2,924 consecutive procedures. Neuroradiology 49:753-759, 2007

8. Earnest F IV, Forbes G, Sandok BA, Piepgras DG, Faust RJ, Ilstrup DM, et al: Complications of cerebral angiography: prospective assessment of risk. AJR Am J Roentgenol 142:247-253, 1984

9. Fournier D, Terbrugge K, Rodesch G, Lasjaunias P: Revascularization of brain arteriovenous malformations after embolization with bucrylate. Neuroradiology 32:497-501, 1990

10. Frydrychowicz A, François CJ, Turski PA: Four-dimensional phase contrast magnetic resonance angiography: potential clinical applications. Eur J Radiol 80:24-35, 2011

11. Gobin YP, Laurent A, Merienne L, Schlienger M, Aymard A, Houdart E, et al: Treatment of brain arteriovenous malformations by embolization and radiosurgery. $\mathbf{J}$ Neurosurg 85:19-28, 1996

12. Grzyska U, Freitag J, Zeumer H: Selective cerebral intraarterial DSA. Complication rate and control of risk factors. Neuroradiology 32:296-299, 1990

13. Heiserman JE, Dean BL, Hodak JA, Flom RA, Bird CR, Drayer BP, et al: Neurologic complications of cerebral angiography. AJNR Am J Neuroradiol 15:1401-1411, 1994

14. Isoda H, Ohkura Y, Kosugi T, Hirano M, Alley MT, Bammer $\mathrm{R}$, et al: Comparison of hemodynamics of intracranial aneurysms between MR fluid dynamics using 3D cine phasecontrast MRI and MR-based computational fluid dynamics. Neuroradiology 52:913-920, 2010

15. Jagannathan J, Sheehan JP, Pouratian N, Laws ER Jr, Steiner L, Vance ML: Gamma Knife radiosurgery for acromegaly: outcomes after failed transsphenoidal surgery. Neurosurgery 62:1262-1270, 2008

16. Jagannathan J, Yen CP, Pouratian N, Laws ER, Sheehan JP: Stereotactic radiosurgery for pituitary adenomas: a comprehensive review of indications, techniques and long-term results using the Gamma Knife. J Neurooncol 92:345-356, 2009

17. Jo KI, Kim JS, Hong SC, Lee JI: Hemodynamic changes in arteriovenous malformations after radiosurgery: transcranial Doppler evaluation. World Neurosurg 77:316-321, 2012

18. Ketkar M, Shrier D: An allergic reaction to intraarterial nonionic contrast material. AJNR Am J Neuroradiol 24:292, 2003 (Letter)
19. Lee CC, Pan DH, Ho DM, Wu HM, Chung WY, Liu KD, et al: Chronic encapsulated expanding hematoma after Gamma Knife stereotactic radiosurgery for cerebral arteriovenous malformation. Clin Neurol Neurosurg 113:668-671, 2011

20. Maruyama K, Kawahara N, Shin M, Tago M, Kishimoto J, Kurita $\mathrm{H}$, et al: The risk of hemorrhage after radiosurgery for cerebral arteriovenous malformations. N Engl J Med 352:146-153, 2005

21. Morcos SK, Thomsen HS: Adverse reactions to iodinated contrast media. Eur Radiol 11:1267-1275, 2001

22. Mukherji SK, Quisling RG, Kubilis PS, Finn JP, Friedman WA: Intracranial arteriovenous malformations: quantitative analysis of magnitude contrast MR angiography versus gradient-echo MR imaging versus conventional angiography. Radiology 196:187-193, 1995

23. Mullan S, Mojtahedi S, Johnson DL, Macdonald RL: Embryological basis of some aspects of cerebral vascular fistulas and malformations. J Neurosurg 85:1-8, 1996

24. Onishi Y, Aoki K, Amaya K, Shimizu T, Isoda H, Takehara Y, et al: Accurate determination of patient-specific boundary conditions in computational vascular hemodynamics using 3D cine phase-contrast MRI. Int J Numer Method Biomed Eng 29:1089-1103, 2013

25. Oppenheim C, Meder JF, Trystram D, Nataf F, Godon-Hardy $\mathrm{S}$, Blustajn J, et al: Radiosurgery of cerebral arteriovenous malformations: is an early angiogram needed? AJNR Am J Neuroradiol 20:475-481, 1999

26. Pandey S, Hakky M, Kwak E, Jara H, Geyer CA, Erbay $\mathrm{SH}$ : Application of basic principles of physics to head and neck MR angiography: troubleshooting for artifacts. Radiographics 33:E113-E123, 2013

27. Pollock BE, Kondziolka D, Lunsford LD, Bissonette D, Flickinger JC: Repeat stereotactic radiosurgery of arteriovenous malformations: factors associated with incomplete obliteration. Neurosurgery 38:318-324, 1996

28. Rao VR, Mandalam KR, Gupta AK, Kumar S, Joseph S: Dissolution of isobutyl 2-cyanoacrylate on long-term followup. AJNR Am J Neuroradiol 10:135-141, 1989

29. Schneider BF, Eberhard DA, Steiner LE: Histopathology of arteriovenous malformations after Gamma Knife radiosurgery. J Neurosurg 87:352-357, 1997

30. Schuster L, Schenk E, Giesel F, Hauser T, Gerigk L, ZabelDu-Bois A, et al: Changes in AVM angio-architecture and hemodynamics after stereotactic radiosurgery assessed by dynamic MRA and phase contrast flow assessments: a prospective follow-up study. Eur Radiol 21:1267-1276, 2011

31. Sheehan JP, Niranjan A, Sheehan JM, Jane JA Jr, Laws ER, Kondziolka D, et al: Stereotactic radiosurgery for pituitary adenomas: an intermediate review of its safety, efficacy, and role in the neurosurgical treatment armamentarium. $\mathbf{J}$ Neurosurg 102:678-691, 2005

32. Sheehan JP, Pouratian N, Steiner L, Laws ER, Vance ML: Gamma Knife surgery for pituitary adenomas: factors related to radiological and endocrine outcomes. J Neurosurg 114:303-309, 2011

33. Steinberg GK, Fabrikant JI, Marks MP, Levy RP, Frankel KA, Phillips MH, et al: Stereotactic heavy-charged-particle Bragg-peak radiation for intracranial arteriovenous malformations. N Engl J Med 323:96-101, 1990

34. Stock KW, Wetzel S, Kirsch E, Bongartz G, Steinbrich W, Radue EW: Anatomic evaluation of the circle of Willis: MR angiography versus intraarterial digital subtraction angiography. AJNR Am J Neuroradiol 17:1495-1499, 1996

35. Sure U, Battenberg E, Dempfle A, Tirakotai W, Bien S, Bertalanffy H: Hypoxia-inducible factor and vascular endothelial growth factor are expressed more frequently in embolized than in nonembolized cerebral arteriovenous malformations. Neurosurgery 55:663-670, 2004

36. Tsuruda J, Saloner D, Norman D: Artifacts associated with 
MR neuroangiography. AJNR Am J Neuroradiol 13:14111422,1992

37. Ward EV, Galizia MS, Usman A, Popescu AR, Dunkle E, Edelman RR: Comparison of quiescent inflow single-shot and native space for nonenhanced peripheral MR angiography. J Magn Reson Imaging 38:1531-1538, 2013

38. Warren DJ, Hoggard N, Walton L, Radatz MW, Kemeny AA, Forster DM, et al: Cerebral arteriovenous malformations: comparison of novel magnetic resonance angiographic techniques and conventional catheter angiography. Neurosurgery 48:973-983, 2001

39. Weintraub MI, Khoury A, Cole SP: Biologic effects of 3 Tesla (T) MR imaging comparing traditional $1.5 \mathrm{~T}$ and 0.6 $\mathrm{T}$ in 1023 consecutive outpatients. J Neuroimaging 17:241245,2007

40. Yen CP, Jain S, Haq IU, Jagannathan J, Schlesinger D, Sheehan J, et al: Repeat Gamma Knife surgery for incompletely obliterated cerebral arteriovenous malformations. Neurosurgery 67:55-64, 2010

41. Yen CP, Varady P, Sheehan J, Steiner M, Steiner L: Subtotal obliteration of cerebral arteriovenous malformations after Gamma Knife surgery. J Neurosurg 106:361-369, 2007

\section{Author Contributions}

Conception and design: Sheehan, Lee, Reardon. Acquisition of data: Lee, Reardon, Ball. Analysis and interpretation of data: Lee, Reardon, Ball, Chen. Drafting the article: Lee, Reardon, Chen, Yen, Xu. Critically revising the article: Sheehan, Lee, Reardon, Chen, Yen, $\mathrm{Xu}$. Reviewed submitted version of manuscript: all authors. Approved the final version of the manuscript on behalf of all authors: Sheehan. Statistical analysis: Sheehan, Lee, Yen, $\mathrm{Xu}$, Wintermark. Administrative/technical/material support: Sheehan, Wintermark. Study supervision: Sheehan, Wintermark.

\section{Correspondence}

Jason Sheehan, Department of Neurological Surgery, University of Virginia Health System, P.O. Box 800212, Charlottesville, VA 22908. email: jsheehan@virginia.edu. 